Brit. J. industr. Med., 1962, 19, 165.

\title{
THE OPTIMAL CLIMATE IN DEPARTMENT STORES
}

\author{
BY \\ J. W. SNELLEN* \\ Department of Occupational Medicine, Netherlands Institute for Preventive Medicine, \\ Leiden, Netherlands
}

(RECEIVED FOR PUBLICATION JANUARY 22, 1962)

The optimal effective temperature for department stores was obtained by collecting temperature and humidity data in six such stores during one full year and by asking several members of the sales staff to give their preference at different periods of the year. Four of the stores gave very good agreement regarding the desirable effective temperature. One store had a different optimum, probably due to local differences in preference, and one store failed to indicate an optimum. This failure could be interpreted in terms of the average optimum derived from the other department stores. Recommendations for optimal effective temperatures for department stores are given. The evaluation of the store climate by the customers did not appear to differ greatly from that of the sales personnel.

A large firm in the Netherlands with many branch establishments consulted the Netherlands Institute for Preventive Medicine concerning the temperature which might be taken as optimal for the sales areas in its department stores. The original request did not specify whether this temperature was to be optimal for commodities, for the staff, or for the customers. Several time-consuming attempts were made to find a relation between the daily air temperatures or the dew-point temperatures and corresponding cash takings, but this effort did not yield any positive results. Since the number of customers influences both sales and indoor climate, a careful examination was made of comparable days with approximately the same turnover. A group of such days was found to include both high and low external temperatures. It was therefore concluded that the customers' buying is independent of climatic conditions outside the store. The investigation was then directed towards determining the optimal climate for the staff, taking their subjective findings as a criterion. This paper deals with the procedure followed and the results obtained with this approach. The questionnaire, which will be discussed in detail, included a question which asked how, in the opinion of the staff, the customers evaluated the climate in the store. Although this part of the investigation did not yield quantitative data, an impression was nevertheless obtained of how the customers rate the climate of a department store.

*Present address: Physiological Laboratory, R.C. University of Nijmegen, Nijmegen, Netherlands.

\section{Method and Results}

A. Climatic Data.-In six branch department stores in different parts of the country, recording thermo-hygrographs were placed in the sales areas. The position was chosen arbitrarily but could be expected to give a fair mean of the indoor climate. The height above the floor was approximately 2 metres. The instruments, which were kept in the same place during one entire year, recorded the temperature and the relative humidity continuously for periods of a week, so that from each department store approximately 50 sheets were collected. This paper describes only those data and procedures which provided the final results. Other relations found between outdoor climate, indoor climate, season, and cash takings are omitted.

The air temperature record showed a marked sawtooth pattern; the daily minimum was at 8.30 a.m. (opening time) and the daily maximum at 6 p.m. (closing time). This pattern held throughout, and was found in all the department stores investigated. The temperature curve was similar to the daily curve of the number of customers, which was available over a period of several days in one of the stores. On certain days during the year when the shops were open till 9 p.m., the maximum temperatures also occurred at 9 p.m. For each day the minimum and the maximum temperatures were read from the instrument charts, together with the corresponding relative humidities. Each temperature was combined with the corresponding relative humidity to calculate the effective temperature. Thus, for each day a minimum 

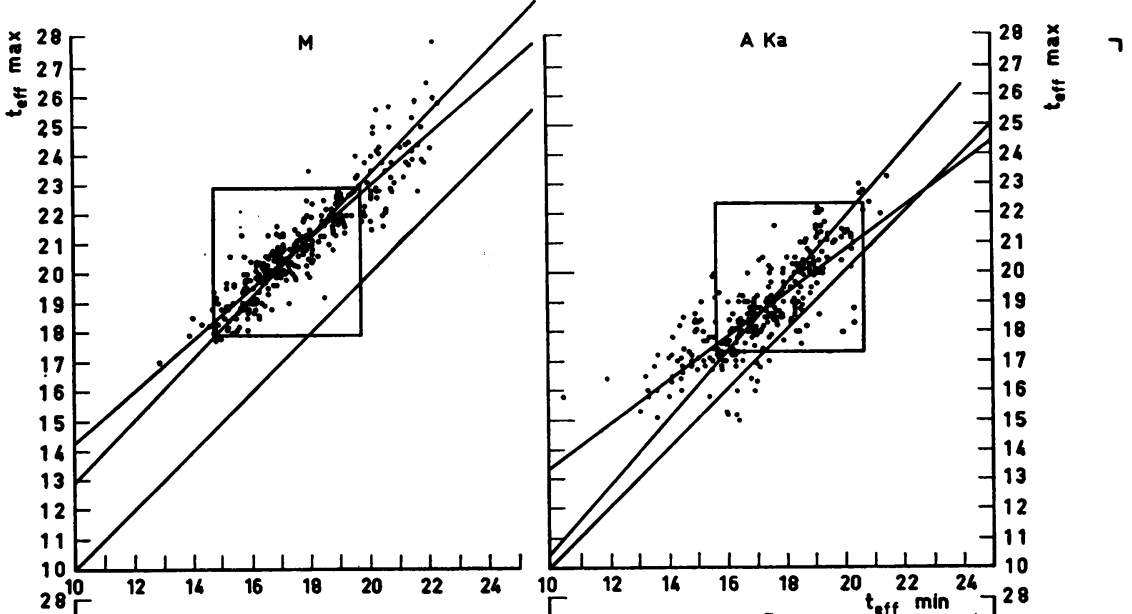

$\mathbf{L}$

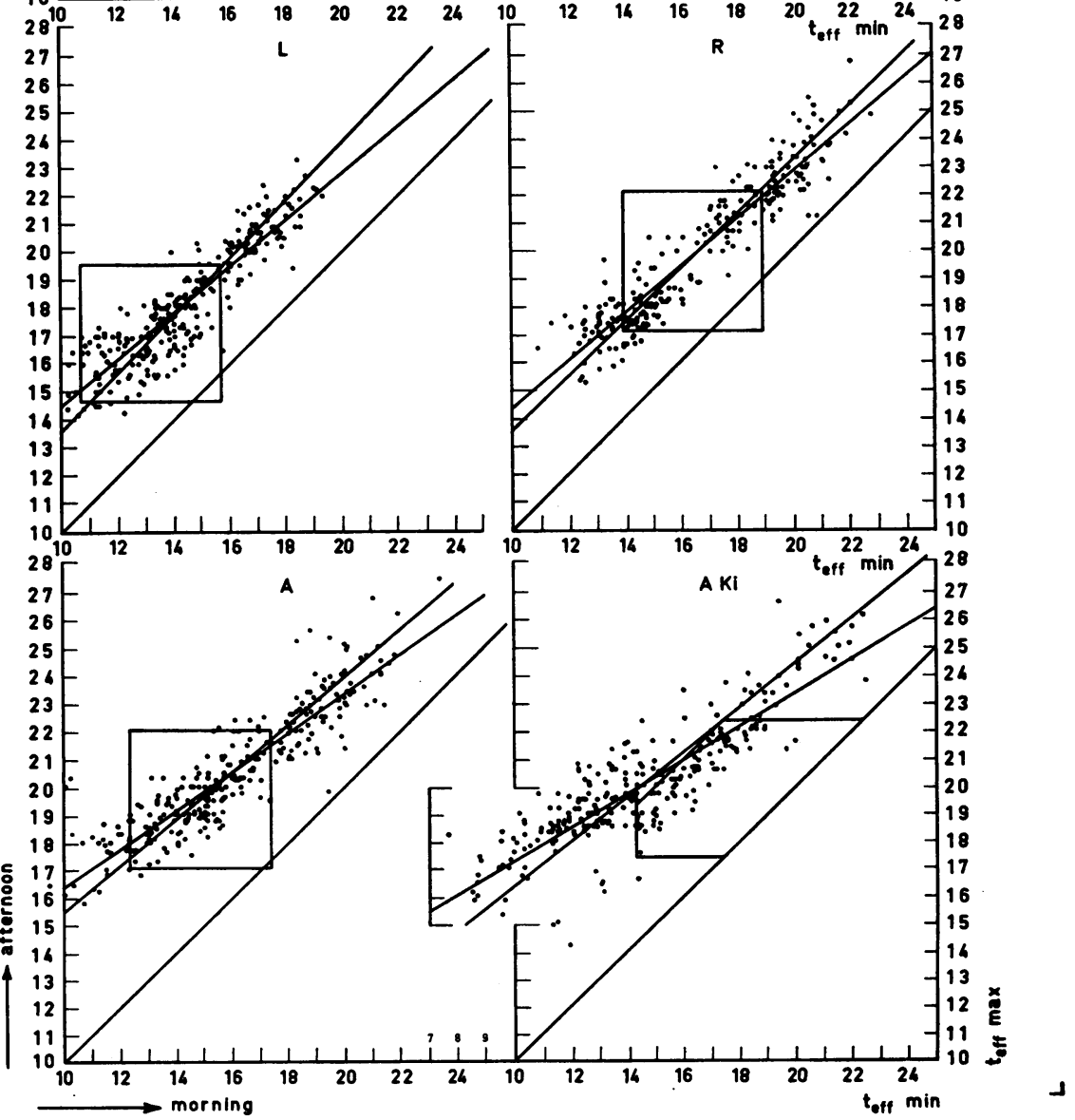

FIG. 1.-Observed morning effective temperatures (minimal tefe) plotted against afternoon effective temperatures (maximal teff) for all the working days of an entire year in six different department stores. The squares indicate the optimal areas. For further details see text. 
and a maximum effective temperature were obtained. These two figures were plotted against each other. For each department store a graph was made which included approximately 300 days, Sundays and holidays being omitted. The six graphs thus plotted are shown in Fig. 1. Although this cannot be seen in the graphs, the lowest points are winter values, and the highest points are summer values.

B. Subjective Findings. - In contrast to the usual procedure (Bedford, 1936; Black, 1954; Ellis, 1953; Leopold, 1947; Raat, 1956; Rowley, Jordan, and Snyder, 1957) of collecting comfort votes of a large sample of a population as well as the climatic factors, in this study a relatively small group of the sales staff were asked to give their general opinion on the climatic conditions throughout the year. In separate interviews, 10 to 15 staff members, all of whom had been working in the department store for more than two years, were asked the following questions after an introductory talk stressing the importance of the staff's opinion in this investigation, urging their co-operation, and requesting them to maintain secrecy about the questionnaire towards their colleagues:

1. Can you say in what period or periods of the year the temperature of the selling department is optimal?

2. Is it sometimes too cold, and if so, in what period of the year?

3. Is it sometimes too warm, and if so, in what period of the year?

4. How do the customers feel about the temperature in the shop compared to your own evaluation?

In almost all cases the interview was held without the presence of the manager. After some hesitation, it was decided to use the word "temperature" instead of "climate" because the former is more colloquial. In most of the department stores the answers were consistent. Although some answered in terms of "spring and autumn" or "the middle of the summer" and others were more precise, mentioning "last half of April, May, and first half of June", it was not difficult to distinguish distinct periods as a common opinion from the answers. Among the various stores a surprising variety of periods of preference appeared: "early spring-late autumn" in store $M$, "mid-summer (when it is hot outside!)" in A Ka, "mid-winter (when it is cold outside!)" in L. In one department store, $\mathrm{A} \mathrm{Ki}$, there was much hesitation after the first question, some saying frankly "never". This store was excluded from the following procedure.

Arrangement of the Data.-The procedure followed will be demonstrated graphically for one 3 department store (M). From all the pairs of effective temperatures of this store, those belonging to the periods mentioned as optimal in the interview were taken. For store $\mathbf{M}$, this was April-May and last half of September-October-first half of November. These pairs of preference are presented in Fig. 2. In this graph, the summer comfort ranges for the optimal effective temperature as given by the Associated Society of Heating and Ventilation Engineers' (A.S.H.V.E.) comfort chart for still air are also indicated. These zones have limited applicability and do not include a distinction between morning and evening values (Winslow and Herrington, 1949). The optimal square obtained from this source was shifted until it fitted best over the observed preferable effective temperature pairs. This was done simply by placing the point of gravity of the square on the average values of the morning and afternoon temperatures, but without rotation of the square. In this way, only the range of the A.S.H.V.E. optimum is used, disregarding its numerical value. The square fits quite well over the dots, indicating that the mean optimal periods of the year, derived from the answers, were not taken either too widely or too narrowly. This newly-established optimal square was placed back in the original graph. The same procedure was carried out for all the branch stores except $\mathrm{A} \mathrm{Ki}$. The new optimal squares are also shown in Fig. 1.

With the optimum for each department store established, it became possible to verify the answers to questions 2 and 3. In store $\mathbf{M}$ there were no complaints about cold, but during the summer it was quite often too warm. This is in agreement with the position of the square with regard to the cloud of dots. In A $\mathrm{Ka}$ it was never too warm during the summer but quite often too cold during the winter. In $L$ the reverse was the case. In $R$ and $A$ there were complaints about both cold and heat. There was good agreement between the answers given and the findings on the graph.

Establishment of the Optimum.-In Fig. 3 all the squares from the five department stores are combined. It can be seen that four squares have approximately the same afternoon value and that this value is approximately $1.5^{\circ} \mathrm{C}$. lower than the summer value for offices. There is, however, a marked difference in morning values. One department store (L) differs from the others. There are some possible explanations for this exceptional pattern:

1. The optimum in store $L$ was indicated by the staff to be in the winter, whereas the other department stores voted for spring and autumn or even midsummer. From the A.S.H.V.E. comfort chart it is known that there is a difference in optimal 


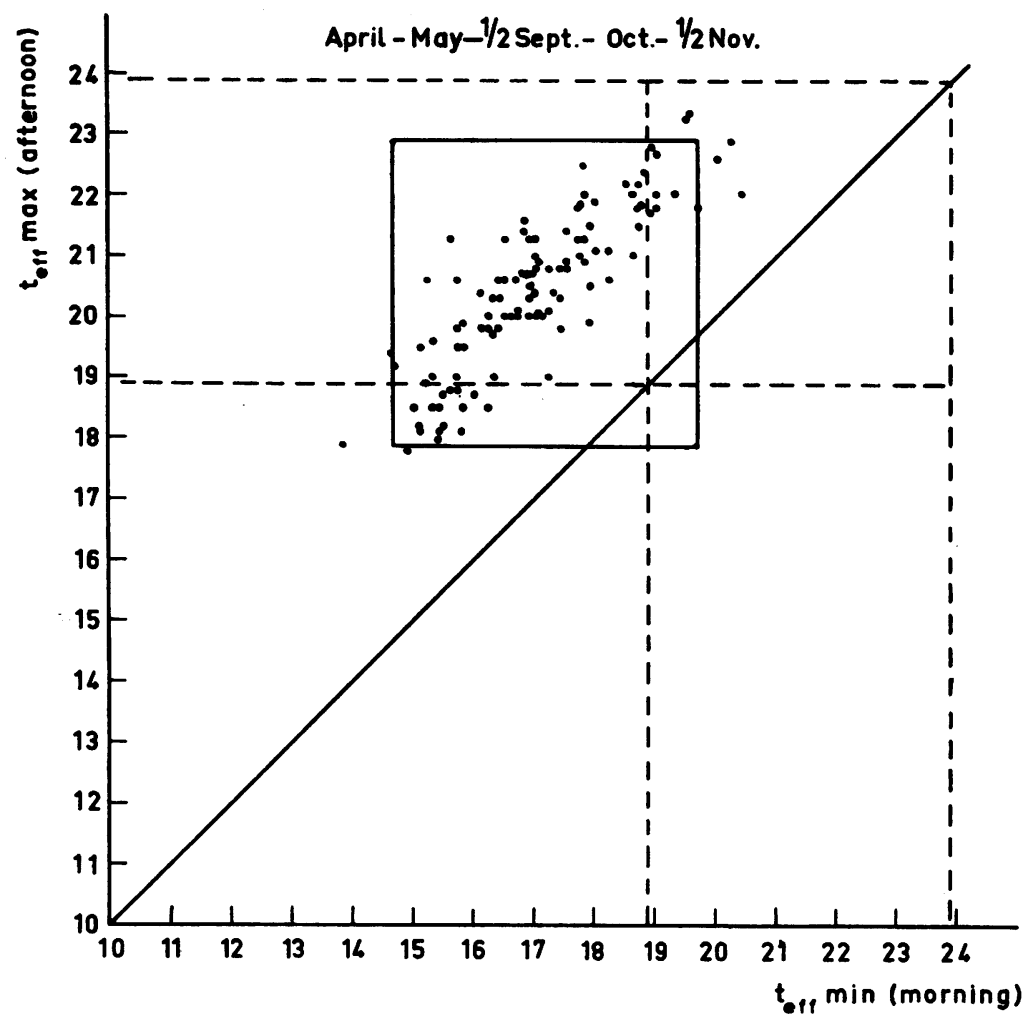

Fig. 2.-Observed morning and afternoon effective temperatures of the preferred periods in department store $\mathbf{M}$, plotted against each other.

temperature between summer and winter, the latter being lower than the former.

2. Store $\mathrm{L}$ is situated in the extreme north of the Netherlands, while $M$ (the highest value) is located in the extreme south. This may be a coincidence which cannot be proved or denied by this investigation, but it is suggestive of a regional difference in subjective sensation. In a comparable study of optimal climates in signal cabins of the Netherlands Railways, located in all parts of the country, a similar observation was made (J. Bosman, personal communication).

The difference between morning (minimum) and afternoon (maximum) optimal temperatures is an incidental observation, but it cannot be concluded that the presence of this difference is optimal in itself. The difference between morning and afternoon temperatures in some department stores $(M, L$, and $R$ ) is relatively constant, independent of the period of the year, as demonstrated by the regression lines which run parallel with the diagonals. It is therefore preferable to assume that this difference is a characteristic feature of the building as it is used (and heated in the winter). It seems reasonable, however, to conclude that some difference between morning and evening temperatures can be accepted as not unfavourable. Since several of the stores show a mean difference of approximately $4^{\circ} \mathrm{C}$., the maximum allowable difference between morning and afternoon temperatures is arbitrarily set at $5^{\circ} \mathrm{C}$.

It is now possible to make recommendations for optimal effective temperatures for department stores as follows:

(a) Morning value (at the store's opening time): $16 \cdot 5^{\circ} \mathrm{C}$., minimum $14 \cdot 0^{\circ} \mathrm{C}$. (maximum equal to afternoon value).

(b) Afternoon value (at the store's closing time): $19 \cdot 5^{\circ} \mathrm{C}$. $\pm 2 \cdot 5^{\circ} \mathrm{C}$.

(c) The difference between morning and afternoon values should not exceed $5^{\circ} \mathrm{C}$.

These values are the mean values of the five department stores investigated, rounded off to the nearest half degree. The tolerance of $2 \cdot 5^{\circ} \mathrm{C}$. of the optimal values is sufficient to "meet local variations in preference. The optimal area is shown in Fig. 1 under A Ki. As can be seen, it is no longer a square. The 


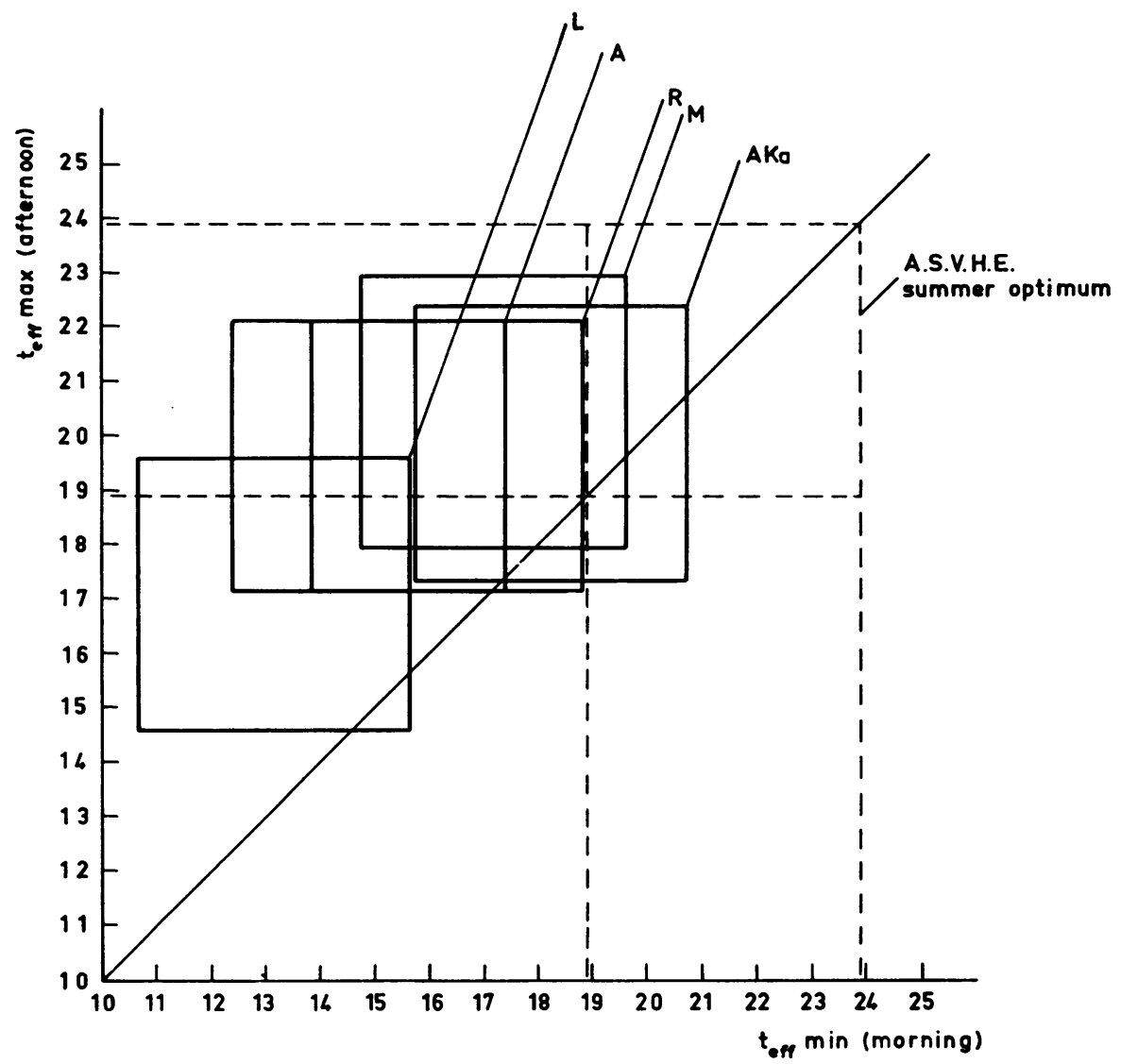

FIG. 3.-The optimal squares of five department stores. Four out of five squares have roughly the same maximal effective temperature. For further details see text.

left upper angle of the square is cut off because in this area the difference is more than $5^{\circ} \mathrm{C}$. To the right upper angle a triangular area is added because it is unnecessary to insist on the presence of a difference between morning and afternoon. In this region the difference between morning and afternoon values is small, but the morning value does not exceed the afternoon maximum of $22 \cdot 0^{\circ} \mathrm{C}$. Theoretically, a situation can exist in which the morning temperature is higher than the afternoon temperature (the area under the diagonal). The size of this area is disregarded.

\section{Discussion}

This study gives an estimate of the optimal conditions in department stores. As is demonstrated in Fig. 1, none of the stores investigated proved to have an adequate system for climatic control. In most cases there was no protection against excessive warmth. Once the above recommendations can be realized in a department store, it becomes interesting to investigate more subtle differences in climatic conditions with more refined techniques. The crucial point in the procedure described here is the subjective element in the establishment of the average of the opinions of the interrogated staff members; the method is not accessible to statistical treatment as used in the "classical" method of establishing climatic optima (Webb, 1959).

A satisfactory evaluation of the climatic situation in a given department store can, however, be made using the method described above. In store $\mathrm{A} \mathrm{Ki}$, where the staff members hesitated to state a preference for periods of the year, only a few of the observed temperatures were within the optimal area. The morning temperatures in the winter were much too low, while the afternoon temperatures were within the optimal range. As a result part of the day was uncomfortable and the change in temperature was too great. During the summer the same 
store showed the (usual) shortcoming of being too warm.

Some remarks on incidental statements of the staff members should be included here. In this study only air temperature and relative humidity could be investigated, but air movement was a serious problem in the proximity of the entrances of several of the department stores. The freshness of the air was often not optimal when the shop was crowded. It is the author's impression, however, that complaints about draughts and odours were more emphatic in those department stores with poor temperature control.

As already mentioned, the staff members were also asked to give their opinion on how the customers evaluated the store climate. This did not yield quantitative information. One of the answers summarizes best the various answers collected: "The customers prefer the temperature to be a little lower than I do. When I feel cold the customers feel fine. On the other hand, when I feel warm the customers do too. It is perhaps better to say that the customers evaluate approximately as I do but they are more sensitive".

When a difference in opinion existed between sales staff and customers this difference did not appear to be large.

\section{REFERENCES}

Bedford, T. (1936). Rep. industr. Hlth Res. Bd (Lond.), No. 76. H.M.S.O., London.

Black, F. W. (1954). J. Instit. H.V.Eng., 22, 319.

Ellis, F. P. (1953). J. Hyg. (Lond.), 51, 386.

Leopold, C. S. (1947). Trans. Amer. Soc. Heat. Vent. Engrs, 53, 295. Raat, J. H. (1956). Comfort and Indoor Climate in Paramaribo. Thesis Utrecht.

Rowley, F. B., Jordan, R. C., and Snyder, W. E. (1957). Trans. Amer. Soc. Heat. Vent. Engrs, 53, 357.

Webb, C. G. (1959). Brit. J. industr. Med., 16, 297.

Webb, C. G. (1959). Brit. . . industr. Med., 16, 297. Temperature and Human Life, p. 107. Princeton University Press, Princeton, New Jersey. 